\title{
Lymph node density in oral cavity cancer: results of the International Consortium for Outcomes Research
}

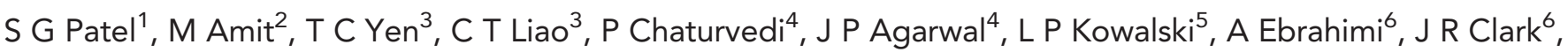
C R Cernea ${ }^{7}$, S J Brandao ${ }^{7}$, M Kreppel ${ }^{8}$, J Zöller ${ }^{8}$, D Fliss ${ }^{9}$, E Fridman ${ }^{9}$, G Bachar ${ }^{10}$, T Shpitzer $^{10}$, V A Bolzoni ${ }^{11}$, $\mathrm{P}$ R Patel ${ }^{12}$, S Jonnalagadda ${ }^{13}, \mathrm{~K}$ T Robbins ${ }^{1}$, J P Shah ${ }^{1}$ and Z Gil ${ }^{\star, 2,14}$ for The International Consortium for Outcome Research (ICOR) in Head and Neck Cancer

${ }^{1}$ Head and Neck Surgery Service, Memorial Sloan Kettering Cancer Center, New York, NY, USA; ${ }^{2}$ Department of Otolaryngology Rambam Medical Center, the Technion, Israel Institute of Technology, Haifa, Israel; ${ }^{3}$ Department of Otorhinolaryngology, Head and Neck Surgery, Chang Gung Memorial Hospital, Taoyuan, Taiwan; ${ }^{4}$ Department of Surgical Oncology, Head and Neck Service, Tata Memorial Hospital, New Delhi, India; ${ }^{5}$ Department of Head and Neck Surgery and Otorhinolaryngology, Hospital AC Camargo, São Paulo, Brazil; ' ${ }^{6}$ yydney Head and Neck Cancer Institute, Royal Prince Alfred Hospital, Sydney, New South Wales, Australia; ${ }^{7}$ Department of Head and Neck Surgery, University of São Paulo Medical School, São Paulo, Brazil; ${ }^{8}$ Department of Oral and Cranio-Maxillo and Facial Plastic Surgery, University of Cologne, Germany; ${ }^{9}$ Department of Otolaryngology, Head and Neck Surgery, Tel Aviv Medical Center, Tel Aviv, Israel; ${ }^{10}$ Department of Otolaryngology, Head and Neck Surgery, Rabin Medical Center, Petach Tikva, Israel; ${ }^{11}$ Department of ENT, University of Brescia, Brescia, Italy; ${ }^{12}$ Department of Otolaryngology, Head and Neck Surgery, University of Auckland, Auckland, New Zealand; ${ }^{13}$ Southern Illinois University School of Medicine, Springfield, IL, USA and ${ }^{14}$ The Laboratory for Applied Cancer Research, the Technion, Israel Institute of Technology, Haifa, Israel

Background: Lymph node density (LND) has previously been reported to reliably predict recurrence risk and survival in oral cavity squamous cell carcinoma (OSCC). This multicenter international study was designed to validate the concept of LND in OSCC.

Methods: The study included 4254 patients diagnosed as having OSCC. The median follow-up was 41 months. Five-year overall survival (OS), disease-specific survival (DSS), disease-free survival (DFS), locoregional control and distant metastasis rates were calculated using the Kaplan-Meier method. Lymph node density (number of positive lymph nodes/total number of excised lymph nodes) was subjected to multivariate analysis.

Results: The OS was $49 \%$ for patients with LND $\leqslant 0.07$ compared with $35 \%$ for patients with $L N D>0.07(P<0.001)$. Similarly, the DSS was $60 \%$ for patients with $L N D \leqslant 0.07$ compared with $41 \%$ for those with $L N D>0.07(P<0.001)$. Lymph node density reliably stratified patients according to their risk of failure within the individual $N$ subgroups $(P=0.03)$. A modified TNM staging system based on LND ratio was consistently superior to the traditional system in estimating survival measures.

Conclusion: This multi-institutional study validates the reliability and applicability of LND as a predictor of outcomes in OSCC. Lymph node density can potentially assist in identifying patients with poor outcomes and therefore for whom more aggressive adjuvant treatment is needed.

*Correspondence: Professor Z Gil; E-mail: ziv@baseofskull.org

Received 23 May 2013; revised 22 August 2013; accepted 26 August 2013; published online 24 September 2013

(c) 2013 Cancer Research UK. All rights reserved 0007-0920/13 
With an estimated 263900 new cases and 128000 deaths per year, squamous cell carcinoma of the oral cavity (OSCC) is among the most common malignant tumours and a significant source of morbidity (Shah and Gil, 2009). Although the incidence of OSCC has decreased in most developed countries over the past decades, it remains a common cancer for both male and female individuals in south-central Asia and in central and Eastern Europe (Yako-Suketomo and Marugame, 2008). The AJCC/UICC staging system for OSCC is based on primary tumour classification $(\mathrm{T})$, on quantification of nodal metastases $(\mathrm{N})$ according to size, number and distribution, and on the presence of distant metastases (M) (Patel and Shah, 2005). In this system, the presence of lymph node metastases has been associated with poor outcome. However, nodal stage by itself was not shown to reliably predict prognosis (Rudoltz et al, 1995; Parsons et al, 1997; Gavilan et al, 2000; Shingaki et al, 2003; Bernier et al, 2005). It is clear that identification of metastatic positive lymph nodes is based on the quality of neck dissection as well as on the sampling procedure (the level of histopathologic scrutiny). As such, the probability of identifying metastasis in lymph nodes relies on the technical performance of both surgeons and pathologists (Bhattacharyya, 1998; Agrama et al, 2003). As limited lymph node dissection may result in pathological understaging, lymph node density (LND) has emerged as an independent prognostic factor for carcinoma of the bladder as well as for OSCC (Stein et al, 2003; Gil et al, 2009). Lymph node density (Gil et al, 2009; Kim et al, 2011; Lee et al, 2012; Passoni et al, 2013), or lymph node ratio (LNR) (Attaallah et al, 2013; Sayed et al, 2013; Wu et al, 2013), equals the ratio of positive lymph nodes to the total number of excised lymph nodes. This ratio attempts to compensate for the potential bias of the sampling method by utilising two information components: the disease regional spread (number of positive nodes) and the surgical treatment (total number of nodes removed during surgery). In this study, which was undertaken by the International Consortium for Outcome Research (ICOR) in Head and Neck Cancer, we aimed to validate the utility of LND as a prognostic tool in patients with OSCC. We also compared the staging system based on LND with the conventional classification used by the American Joint Committee on Cancer (AJCC) (Edge SB).

\section{MATERIALS AND METHODS}

Patients and methods. Our study cohort included anonymised data on 4254 patients from 11 cancer centers worldwide. The study was approved by the local institutional review board (IRB) committees of the participating centres. Data were collected retrospectively on all patients by using uniform database templates to ensure consistent data collection. Criteria for patient inclusion were as follows: histopathological diagnosis of OSCC, surgical treatment with a neck dissection involving levels I-III, I-IV or I-V as described by the American Head and Neck Society, available pathological report and follow-up data and $>6$ months follow-up or earlier death or recurrence (Robbins et al, 2008). Table 1 presents the demographic and clinical data of these patients. Their follow-up ranged from 2 to 322 months (median 41 months); follow-up period for $\mathrm{N}+$ patients was 4-322 (median 46 months).

Histopathological analysis. A total of 118261 lymph nodes were evaluated, of which 6353 (5.3\%) were positive. The tissues were evaluated at each centre by a certified head and neck pathologist. Specimen dissection, tissue sampling, fixing, cutting and microscopic examination of the primary tumour were carried out in a similar way according to the guidelines for the histopathological assessment (group, 2007). There were 1280 (30\%) patients with 1391 lymph nodes, which had documented evidence of extracapsular spread (ECS).

\begin{tabular}{|c|c|c|}
\hline Variable & No. of patients & $\%$ \\
\hline \multicolumn{3}{|l|}{ Mean age, year } \\
\hline $52.63 \pm 14.6(14-99)$ & 4254 & 100 \\
\hline \multicolumn{3}{|l|}{ Gender } \\
\hline $\begin{array}{l}\text { Male } \\
\text { Female }\end{array}$ & $\begin{array}{l}2815 \\
1439\end{array}$ & $\begin{array}{l}60.1 \\
39.9\end{array}$ \\
\hline \multicolumn{3}{|l|}{ Treatment } \\
\hline $\begin{array}{l}\text { Surgery } \\
\text { Surgery + RT } \\
\text { Surgery + CRT } \\
\text { Surgery + RT + Erbitux }\end{array}$ & $\begin{array}{r}1297 \\
2245 \\
553 \\
159\end{array}$ & $\begin{array}{r}22 \\
58 \\
15 \\
5\end{array}$ \\
\hline \multicolumn{3}{|c|}{ Type of neck dissection } \\
\hline $\begin{array}{l}\text { Elective } \\
\text { Therapeutic }\end{array}$ & $\begin{array}{l}2434 \\
1820\end{array}$ & $\begin{array}{l}52 \\
48\end{array}$ \\
\hline \multicolumn{3}{|c|}{ Extent of neck dissection } \\
\hline $\begin{array}{l}\text { I-III/IV } \\
\text { I-V } \\
\text { Radical ND } \\
\text { Bilateral ND }\end{array}$ & $\begin{array}{r}2746 \\
525 \\
327 \\
656\end{array}$ & $\begin{array}{r}60.7 \\
13.2 \\
9.9 \\
16\end{array}$ \\
\hline \multicolumn{3}{|l|}{ T classification } \\
\hline $\begin{array}{l}1 \\
2 \\
3 \\
4\end{array}$ & $\begin{array}{r}613 \\
1374 \\
623 \\
1644\end{array}$ & $\begin{array}{l}13 \\
30 \\
15 \\
42\end{array}$ \\
\hline \multicolumn{3}{|l|}{$\mathbf{N}$ classification } \\
\hline $\begin{array}{l}\text { N0 } \\
\text { N1 } \\
\text { N2a } \\
\text { N2b } \\
\text { N2c } \\
\text { N3 }\end{array}$ & $\begin{array}{r}2268 \\
652 \\
88 \\
988 \\
246 \\
12\end{array}$ & $\begin{array}{c}43.3 \\
15.3 \\
2 \\
23.2 \\
6 \\
0.2\end{array}$ \\
\hline \multicolumn{3}{|l|}{ Overall TNM stage } \\
\hline $\begin{array}{l}\text { I } \\
\text { II } \\
\text { III } \\
\text { IV }\end{array}$ & $\begin{array}{r}4644 \\
799 \\
668 \\
2323\end{array}$ & $\begin{array}{r}9 \\
13 \\
16 \\
62\end{array}$ \\
\hline \multicolumn{3}{|l|}{ Follow-up (months) } \\
\hline $\begin{array}{l}\text { Mean } \\
\text { Median } \\
\text { Range }\end{array}$ & $\begin{array}{c}49.6 \pm 44 \\
41 \\
2-322\end{array}$ & 100 \\
\hline
\end{tabular}

Statistical analysis. Five-year overall survival (OS), diseasespecific survival (DSS), disease-free survival (DFS), locoregional control and distant metastasis rates were calculated using the Kaplan-Meier method, and the difference in survival rate was assessed by the log-rank test (Kaplan and Meier, 1958; Peto et al, 1977). OS was measured from the date of surgery to the date of death or last follow-up. The DSS was calculated from the time of diagnosis to death resulting from OSCC. The univariate association between individual clinical features and survival was determined with the log-rank test (Mantel, 1966). A multivariate analysis using the Cox proportional hazards regression model was performed to compare the factors with prognostic potential as indicated by univariate analyses (Cox, 1972; Gil et al, 2007). The limit of 
significance for all analyses was defined as $P<0.05$; two-sided statistical tests were used in all calculations. All data were analysed using StatView 5.0 software package (SAS Institute Inc, Cary, NC, USA) and confirmed by an independent statistician (ES and CR) using the IBM SPSS Statistics package (IBM Corporation, Armonk, NY, USA). Variables used to stratify lymph node metastases included the total number of lymph nodes dissected $(<20$ or $\geqslant 20$ ), pathological $\mathrm{N}(\mathrm{pN})$ classification ( $\mathrm{pN} 0, \mathrm{pN} 1, \mathrm{pN} 2 \mathrm{a}, \mathrm{pN} 2 \mathrm{~b}$, $\mathrm{pN} 2 \mathrm{c}$ or $\mathrm{pN} 3$ ), ECS (absent or present) of tumour and the ratio of the number of positive-to-total number of lymph nodes (the LND or LNR). Nodal yield of $<, \geqslant 20$ was selected because its prognostic implication was previously described (Ebrahimi et al, 2011). Previous studies showed that once 18-20 nodes are surgically removed and pathologically analysed, the neck is likely to be correctly staged and occult microscopic disease adequately treated (Ebrahimi et al, 2011). The seventh edition of the tumournode-metastasis staging system for oral cavity SCC was used for TNM staging (Edge et al, 2010). Time-dependent receiver operating characteristic (ROC) curves, area under the curve (AUC) of the ROC curve, sensitivity, specificity, as well as likelihood ratios were calculated to determine which LND best defines different risk groups of OSCC subjects (Heagerty et al, 2000; Etzioni et al, 2003; Xiao et al, 2011; Espin et al, 2012). A cutoff of 0.07 was selected by time-dependent ROC curve analysis for disease-specific death (AUC (c-index) $=0.79$, 95\% CI $0.53-$ 0.94 , sensitivity and specificity for 5 years DSS $91 \%$ and $84 \%$, respectively). To test the stability of the cutoff point, we also performed 1000 times bootstrapping (Chen and George, 1985; Efron, 1994). Each time, we generated a risk-score formula on 650 randomly selected participants from the data set. The average and standard deviation of the 1000 threshold values were $0.066 \pm 0.012$. On the basis of these cutoff points, the all-combined 1986 patients were classified into high-risk or low-risk groups. The mean with an empirical standard error using $1000 \operatorname{logHRs}$ was $1.42 \pm 0.34$, and the empiric 95\% CI was between 1.21 and 1.65. Correlation analysis was performed using the Pearson's coefficient of regression. We compared a modified TNM staging system based on LND with the traditional TNM staging system (based on standard $\mathrm{pN}$ classification) (Supplementary Table 1).

Investigation for the presence of between-centre heterogeneity was performed using a two-stage random effects model (Stukel et al, 2001). At the first stage of analysis, the difference in prognosis between LND $>0.07$ and $\mathrm{LND}<0.07$ groups was determined for each centre. In the second stage, the centre-specific effect estimates were introduced into a random effects model as described by (DerSimonian and Laird, 1986), which allows for unexplained sources of heterogeneity between centres. Heterogeneity across centres was assessed using Cochran's $Q$ test $(P<0.1$ was considered statistically significant, given the test has limited power) and quantified using the $I^{2}$ measure (the percentage of total variation across centres attributable to heterogeneity rather than chance) (Higgins and Thompson, 2002).

The reporting of this study conforms to Strengthening the Reporting of Observational Studies in Epidemiology guidelines for reporting of observational studies (flowchart not presented) (von Elm et al, 2007).

\section{RESULTS}

A total of 4254 OSCC patients treated at 11 tertiary cancer centres were eligible for inclusion into the study (Table 1). Elective neck dissection (neck dissection for clinically stage N0) was performed on 2435 patients (57\%), and therapeutic neck dissection (neck dissection for clinically stage $\mathrm{N}+$ ) was performed on 1819 patients (43\%). Supplementary Figure 1 summarises the management and outcome of the study patients. Kaplan-Meier estimates of 5-year OS, DFS and DSS for all study patients were 56\%, 55\% and 64\%, respectively.

Histopathological examination of the neck dissection specimens revealed 1986 (46.7\%) patients with positive lymph nodes. There were 2268 patients with pN0 disease (53.3\%), 652 patients with $\mathrm{pN} 1$ disease (15.3\%), 1322 patients with $\mathrm{pN} 2$ disease $(31.2 \%)$ and 12 patients with $\mathrm{pN} 3$ disease $(0.2 \%)$. The overall rate of occult neck metastases was $21 \%$. Supplementary Table 2 shows the rate of neck metastases for each $\mathrm{T}$ classification. The 5 -year OS was $66 \%$ for patients with pathologically negative neck lymph nodes and $43 \%$ for those with positive nodes $(P<0.0001)$. The 5 -year DSS was $74 \%$ for patients with pathologically negative neck nodes and $52 \%$ for those with positive nodes $(P<0.0001)$. Supplementary Figure 2 shows the Kaplan-Meier curves of OS and DSS according to the N status. ECS was present in 1280 patients and it also had a significant effect on OS and DSS on univariate analysis $(P<0.001)$.

We further analysed the group of patients with $\mathrm{N}$ positive disease $(n=1986)$. In each neck dissection specimen, there were 2-104 (mean \pm s.d., $39 \pm 23$ ) lymph nodes and 1-34 (3.1 \pm 4.6$)$ of them were positive. The median LND was 0.064 (range, $0.009-1$ ). Univariate analysis revealed that margin status (negative, $<5 \mathrm{~mm}$ or positive), pathological $\mathrm{T}$ stage, $\mathrm{pN}$ stage, ECS, overall TNM stage and treatment group (surgery, surgery and radiation therapy or surgery and chemoradiation) were significant predictors of 5-year OS, DSS and DFS (Ambrosch et al, 1995; Fukano et al, 1997; Liao et al, 2012a,b). Most importantly, LND was also found to be a significant predictor of OS and DSS (Figure 1), as well as DFS, local control, locoregional control and distant metastasis rate (Figure 2). For patients with an LND $\leqslant 0.07$, the 5 -year OS was $49 \%$ compared with $35 \%$ in patients with an LND $>0.07(P<0.001)$. Similarly, the 5 -year DSS was $60 \%$ for patients with an LND $\leqslant 0.07$ compared with $41 \%$ in patients with an LND $>0.07(P<0.001)$. When the threshold value of 0.066 based on the bootstrapping results was applied to the analysis, comparable log-rank $P$-value and HR were observed (Supplementary Figure 3).

To further evaluate the impact of clinicopathological variables in a multivariate model, we first analysed the data without LND. The variables compared were gender, age, depth of invasion, margin status, $\mathrm{T}$ stage, $\mathrm{pN}$ stage, overall pathological stage, ECS, total number of lymph nodes excised and treatment group. Gender $(P<0.0001)$, age $(P=0.0006)$, margins status $(P<0.0001)$, pathological $\mathrm{T}$ stage $(P<0.0001), \mathrm{pN}$ classification $(P<0.0001)$ and treatment group $(P=0.0001)$ were significant predictors of OS. The significant DSS predictors were gender $(P<0.0001)$, age $(P=0.04)$, margin status $(P<0.0001)$, pathological $\mathrm{T}$ stage $(P<0.0001), \mathrm{pN}$ classification $(P=0.001)$ and treatment group $(P=0.006)$. Next, we added the LND variable to the multivariate model with a separation threshold of 0.07 (Table 2). The results showed that an LND $>0.07$ was independently associated with a poorer OS and DSS ( $P=0.019$ and $P=0.004$, respectively). Other predictors that remained significant for both OS and DSS were margin status, $\mathrm{T}$ stage, $\mathrm{pN}$ classification and treatment group. An $\mathrm{LND} \leqslant 0.07$ was associated with better local control, locoregional control and DFS in a multivariate analysis $(P<0.01$, Supplementary Table 3). Multivariate analysis showed that only treatment group, overall TNM stage and LND were significant predictors of distant metastasis $(P<0.05$, Supplementary Table 3$)$. Most importantly, the proportional hazard fits ( - Loglikelihood value) in all of the analyses (including OS, DSS, RFS, distant metastasis-free survival, local and locoregional control rates) were better for the model that included LND than the one without it (Supplementary Table 1). Similarly, when neck nodal status classified according to N1, N2 and N3 was added to the model as an independent variable instead of being subclassified according to $\mathrm{pN} 1, \mathrm{pN} 2 \mathrm{a}, \mathrm{pN} 2 \mathrm{~b}, \mathrm{pN} 2 \mathrm{c}$ and $\mathrm{pN} 3$, LND remained a significant predictor of outcome. Likewise, when patients with $\mathrm{pN} 2$ and $\mathrm{pN} 3$ 

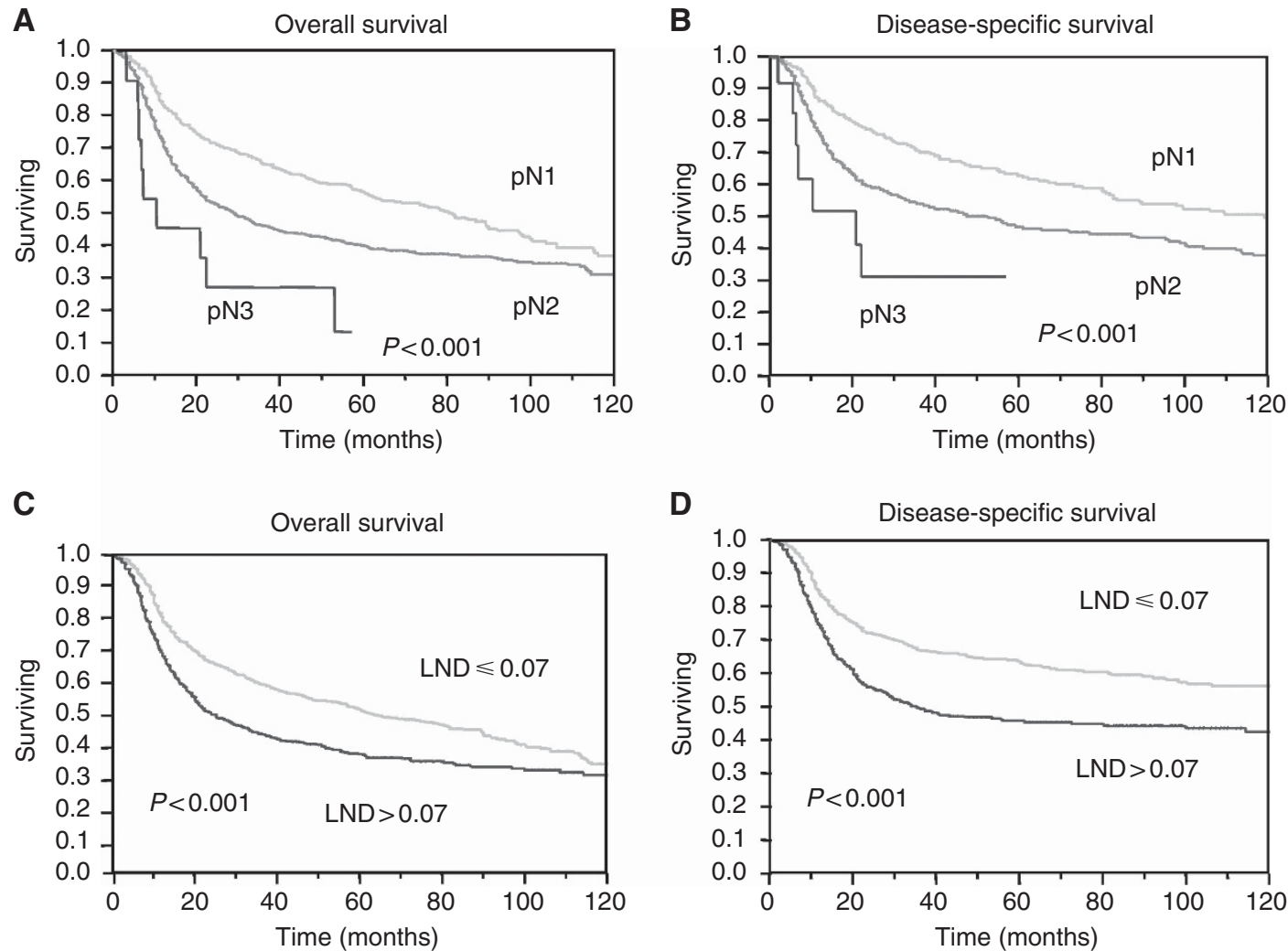

Figure 1. Five-year overall survival and disease-specific survival rates calculated using the Kaplan-Meier method in patients with positive neck nodes. (A and B) Using TNM nodal classification ( $P<0.001)$; ( and $\mathbf{D})$ using LND with a cutoff point of $0.07(P<0.001)$. An analysis using LND separation point of 0.066 (based on the bootstrapping analysis) yielded similar results.

A

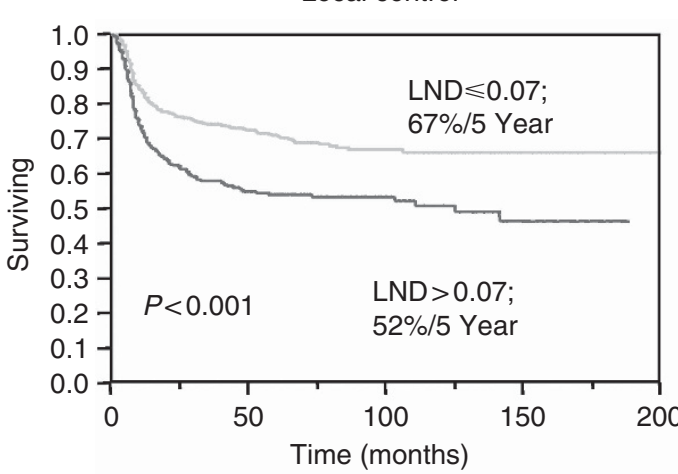

C

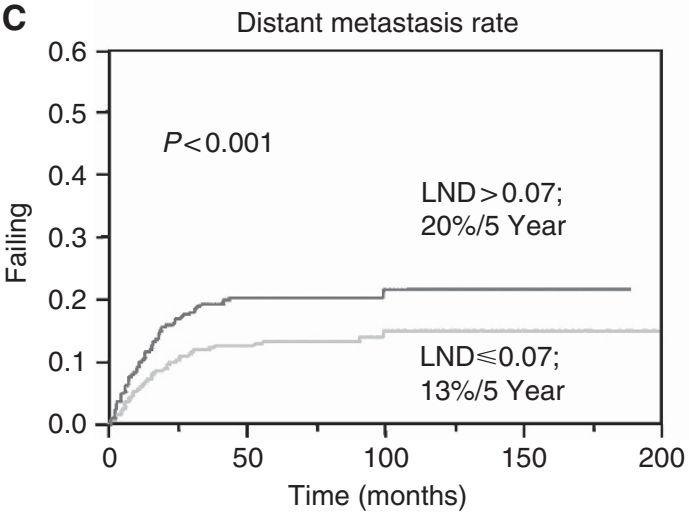

B

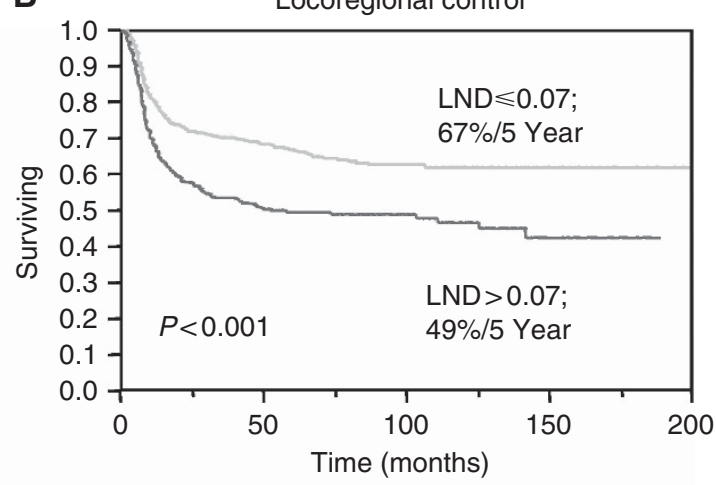

D

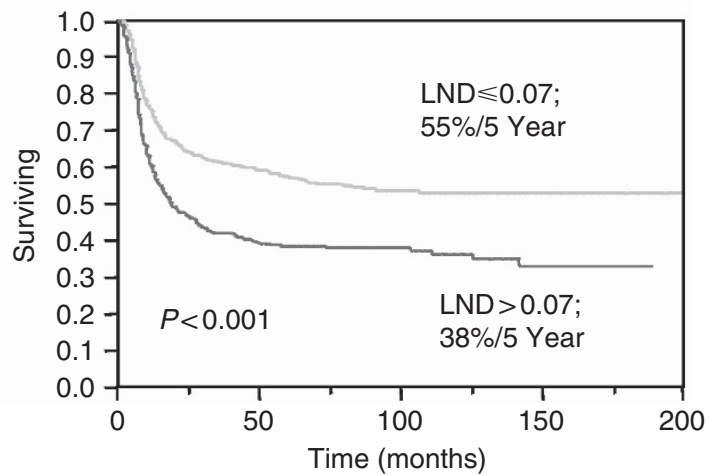

Figure 2. Five-year (A) local control, (B) locoregional control and (C) distant metastasis failure and (D) disease-free survival rates calculated by the Kaplan-Meier method in patients with positive neck nodes. The LND model had a cutoff point of $0.07(P<0.001)$. Similar results were retrieved using LND cutoff point of 0.066 . 
Table 2. Multivariate analysis of prognostic factors for overall and disease-specific survival $(n=1986)$

\begin{tabular}{|c|c|c|c|c|c|c|}
\hline \multirow[b]{2}{*}{ Variable } & \multicolumn{3}{|c|}{ Overall survival } & \multicolumn{3}{|c|}{ Disease-specific survival } \\
\hline & $P$ & Adjusted HR & $95 \% \mathrm{Cl}$ & $\boldsymbol{P}$ & Adjusted HR & $95 \% \mathrm{Cl}$ \\
\hline \multicolumn{7}{|l|}{ Gender } \\
\hline $\begin{array}{l}\text { Male } \\
\text { Female }\end{array}$ & $<0.0001$ & $\begin{array}{l}1 \\
0.33\end{array}$ & $0.24-0.52$ & 0.0009 & $\begin{array}{l}1 \\
0.49\end{array}$ & $0.2-0.77$ \\
\hline \multicolumn{7}{|l|}{ Age } \\
\hline $\begin{array}{l}<65 \\
\geqslant 65\end{array}$ & 0.0009 & $\begin{array}{l}1 \\
2.25\end{array}$ & $1.25-3.56$ & 0.03 & $\begin{array}{l}1 \\
1.8\end{array}$ & $1.2-3.1$ \\
\hline \multicolumn{7}{|c|}{ Depth of invasion } \\
\hline $\begin{array}{l}<4 \\
4-8 \\
\geqslant 8\end{array}$ & 0.52 & NA & NA & 0.28 & NA & NA \\
\hline \multicolumn{7}{|l|}{ Margins } \\
\hline $\begin{array}{l}\text { Negative } \\
\text { Close } \\
\text { Positive }\end{array}$ & $<0.0001$ & $\begin{array}{l}1 \\
2.75 \\
3.14\end{array}$ & $\begin{array}{c}1.63-14.5 \\
1.9-4.1\end{array}$ & $<0.0001$ & $\begin{array}{l}1 \\
1.46 \\
1.89\end{array}$ & $\begin{array}{l}1.2-3.6 \\
1.4-3.1\end{array}$ \\
\hline \multicolumn{7}{|c|}{ Pathologic T classification } \\
\hline $\begin{array}{l}\text { T1 } \\
\text { T2 } \\
\text { T3 } \\
\text { T4 }\end{array}$ & $<0.0001$ & $\begin{array}{l}1 \\
2.05 \\
2.26 \\
3.33\end{array}$ & $\begin{array}{l}1.3-3.6 \\
1.5-4.1 \\
2.3-6.1\end{array}$ & $<0.0001$ & $\begin{array}{l}1 \\
1.9 \\
2.5 \\
3.1\end{array}$ & $\begin{array}{l}1.1-3.9 \\
1.4-5.7 \\
1.7-4.7\end{array}$ \\
\hline \multicolumn{7}{|c|}{ Pathologic N classification } \\
\hline $\begin{array}{l}\text { N1 } \\
\text { N2a } \\
\text { N2b } \\
\text { N2c } \\
\text { N3 }\end{array}$ & 0.004 & $\begin{array}{l}1 \\
1.3 \\
2.2 \\
3.1 \\
3.9\end{array}$ & $\begin{array}{c}1.03-1.9 \\
1.5-2.8 \\
1.8-4.9 \\
1.2-7.1\end{array}$ & 0.004 & $\begin{array}{l}1 \\
1.6 \\
1.9 \\
2.4 \\
3.2\end{array}$ & $\begin{array}{c}1.2-3 \\
1.3-4.1 \\
1.6-7.1 \\
1.6-5.2\end{array}$ \\
\hline \multicolumn{7}{|c|}{ Extracapsular spread } \\
\hline $\begin{array}{l}\text { No } \\
\text { Yes }\end{array}$ & 0.2 & NA & NA & 0.25 & NA & NA \\
\hline \multicolumn{7}{|c|}{ Total number of lymph nodes } \\
\hline $\begin{array}{l}<20 \\
\geqslant 20\end{array}$ & 0.83 & NA & NA & 0.56 & NA & NA \\
\hline \multicolumn{7}{|c|}{ Treatment group } \\
\hline $\begin{array}{l}\text { Surgery } \\
\text { Surgery + RT } \\
\text { Surgery + CRT }\end{array}$ & 0.0005 & $\begin{array}{l}1 \\
0.59 \\
0.71\end{array}$ & $\begin{array}{c}0.44-0.73 \\
0.6-0.8\end{array}$ & 0.01 & $\begin{array}{l}1 \\
0.7 \\
0.77\end{array}$ & $\begin{array}{l}0.5-0.9 \\
0.5-0.9\end{array}$ \\
\hline \multicolumn{7}{|c|}{ Lymph node density } \\
\hline $\begin{array}{l}\leqslant 0.07 \\
>0.07\end{array}$ & 0.019 & $\begin{array}{l}1 \\
1.7\end{array}$ & $1.2-1.9$ & 0.004 & $\begin{array}{l}1 \\
1.62\end{array}$ & $1.4-1.9$ \\
\hline \multicolumn{7}{|c|}{ Overall TNM stage } \\
\hline $\begin{array}{l}\text { I } \\
\text { II } \\
\text { III } \\
\text { IV }\end{array}$ & 0.69 & NA & NA & 0.8 & NA & NA \\
\hline \multicolumn{7}{|c|}{ LND-based TNM stage } \\
\hline $\begin{array}{l}\text { I } \\
\text { II } \\
\text { III } \\
\text { IV }\end{array}$ & 0.03 & $\begin{array}{l}1 \\
1.5 \\
2.4 \\
2.9\end{array}$ & $\begin{array}{l}1.2-2.2 \\
1.3-5.4 \\
1.5-6.1\end{array}$ & 0.03 & $\begin{array}{l}1 \\
2 \\
4.1 \\
4.8\end{array}$ & $\begin{array}{l}1.6-4.2 \\
3.1-8.1 \\
3.6-8.2\end{array}$ \\
\hline
\end{tabular}


were combined, LND remained a significant independent predictor of outcome $(P=0.01)$, whereas the $\mathrm{pN}$ classification did not. We also used the other separation point in this analysis, as suggested by the bootstrapping of the LND thresholds 0.066 (see Materials and methods); this analysis yielded similar results. Two-stage random effects analysis was used to investigate between-centre heterogeneity. We confirmed the absence of significant institutional heterogeneity for OS $\left(I^{2}=0 \% ; P=0.76\right)$ and DSS $\left(I^{2}=0 \% ; P=0.4\right)$. To rule out colinearity between LND and number of positive nodes, we repeated the multivariate analysis without total number of nodes and number of positive nodes. In this analysis, LND $>0.07$ remained significant for OS $(P=0.008, \mathrm{HR}=2.6)$ and DSS $(P=0.0006, \mathrm{HR}=2.4)$. Furthermore, after removing patients with $<20$ lymph nodes from our analysis, LND $>0.07$ remained a significant predictor for DSS, $P=0.0073$.

In order to further assess the ability of LND to predict treatment response in a more homogeneous population, and to account for the potential impact of adjuvant treatment, we performed a subgroup multivariate analysis on each of the following treatment groups: patients undergoing surgery alone $(n=183$, due to patients' refusal to radiotherapy or prior irradiation), patients undergoing postoperative radiotherapy $(n=1247)$ and patients who received adjuvant chemoradiation $(n=556)$. LND emerged as an independent predictor of both OS and DSS on multivariate analysis in patients receiving postoperative radiotherapy without chemotherapy $(P=0.02$ and $P=0.01$, respectively) and surgery alone $(P=0.005$ and $P=0.007$, respectively). In patients receiving postoperative chemoradiation, LND successfully predicted DSS $(P=0.03)$ but not $\mathrm{OS}(P=0.13$, Figure 3$)$.

Similar survival analyses performed separately on patients undergoing elective neck dissections $(\mathrm{cN}-)$ and therapeutic neck dissections $(\mathrm{cN}+)$ revealed the same results (Supplementary Figure 1).
Comparison of the neck dissection and LND variables between these groups is shown in Supplementary Table 4. Overall, LND was a significant predictor of OS and DSS on a multivariate analysis in both of these groups $(P<0.01)$.

As previous studies had demonstrated the ability of LND to distinguish between individual $\mathrm{pN}$ subgroups, we further investigated whether LND could identify high- and low-risk patients within each $\mathrm{pN} 1$ or $\mathrm{pN} 2$ classification groups. Figure 4 demonstrates that LND at a cutoff of 0.07 could distinguish between highrisk- and low-risk patients within each $\mathrm{pN} 1$ and $\mathrm{pN} 2$ patients. The pN3 subgroup could not be similarly analysed, as it consisted of only 12 patients.

Finally, we compared a modified TNM staging system based on LND, to the traditional TNM staging system (based on standard $\mathrm{pN}$ classification, see Supplementary Table 1). Both the traditional and new staging systems were introduced into the multivariate model. Notably, the new TNM staging system that was based on the LND ratio was consistently superior to the traditional system in all of the selected survival measures (Table 2 and Supplementary Table 3 for the multivariate analysis). Supplementary Figure 4 shows the Kaplan-Meier curves of OS and DSS according to the disease stage in the TNM staging system based on LND and the traditional TNM staging.

\section{DISCUSSION}

The mainstay of treatment of patients with OSCC is surgical ablation of the primary tumour. Neck dissection is performed as an elective procedure or when the clinical or radiological examination shows evidence of lymph node metastases (Gil et al, 2009). Tumour stage, margin status, depth of invasion and the presence of neck metastases are significant prognostic factors in this

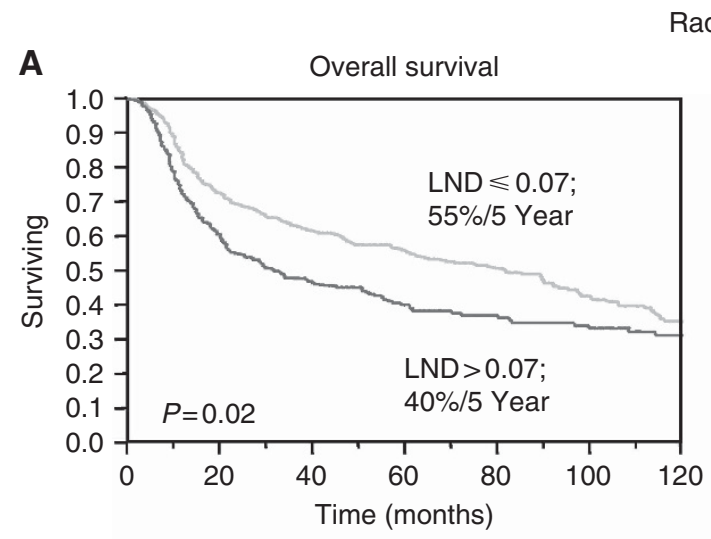

Radiation
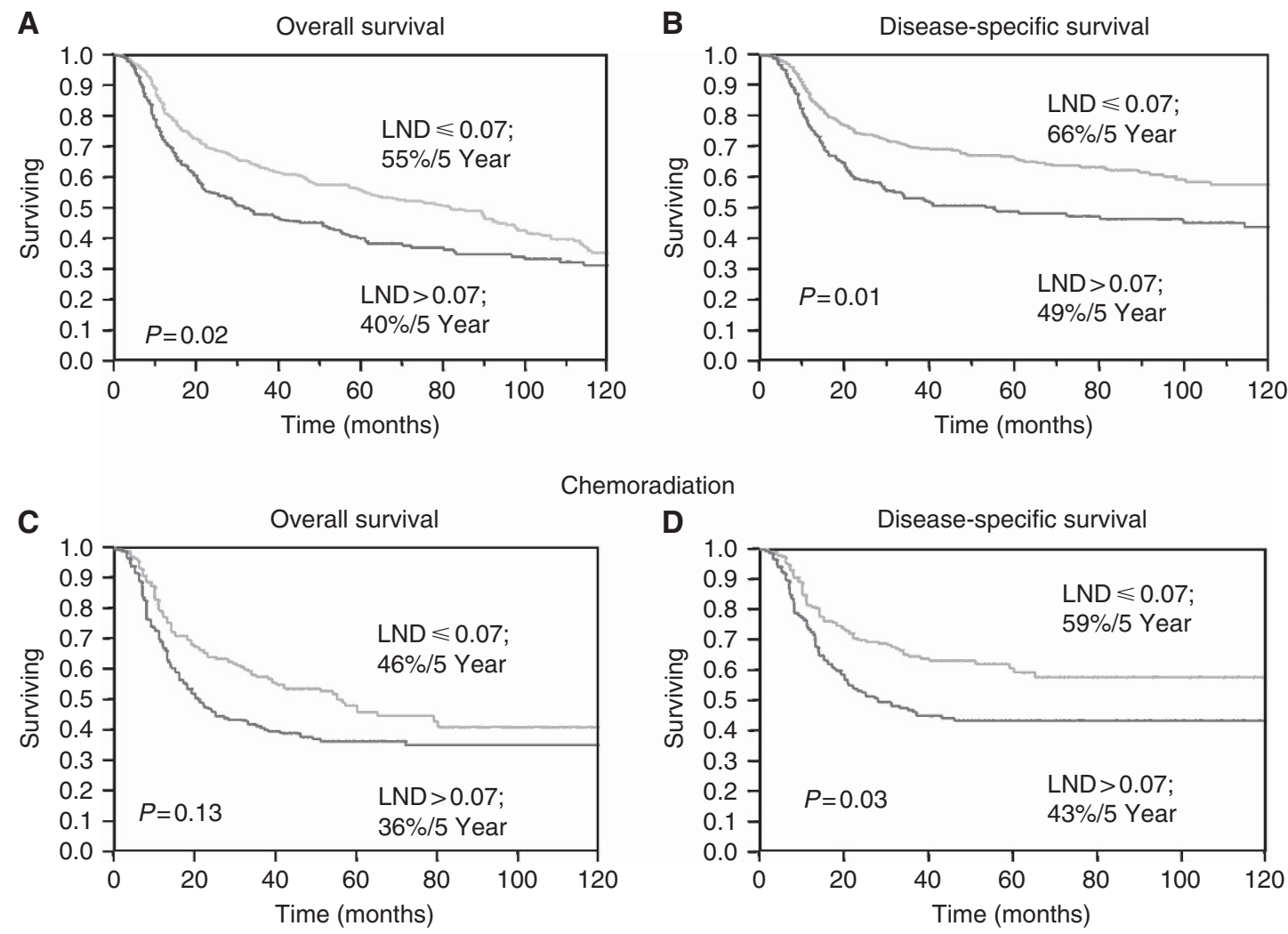

Figure 3. (A-D) Kaplan-Meier curves of overall and disease-specific survival according to the treatment modality. The difference in survival rate was assessed by the log-rank test. 
A

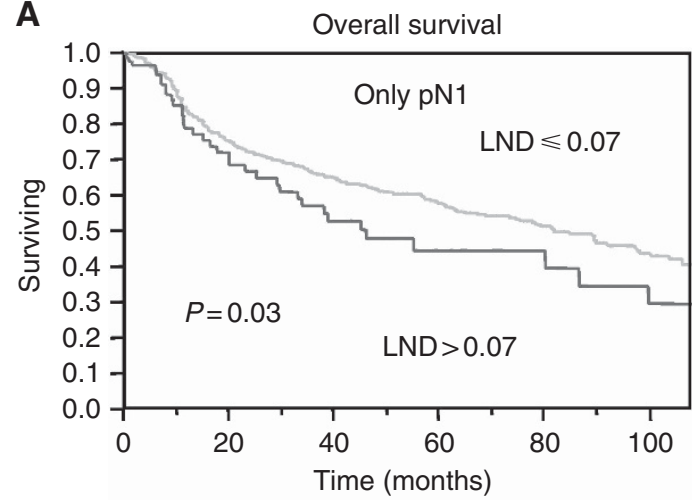

C

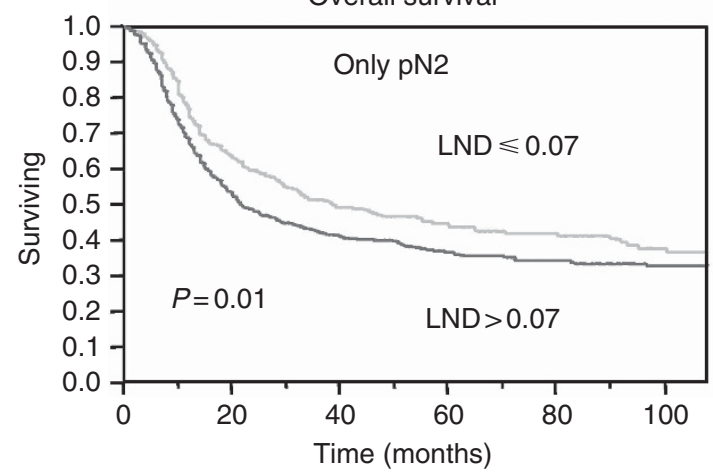

B

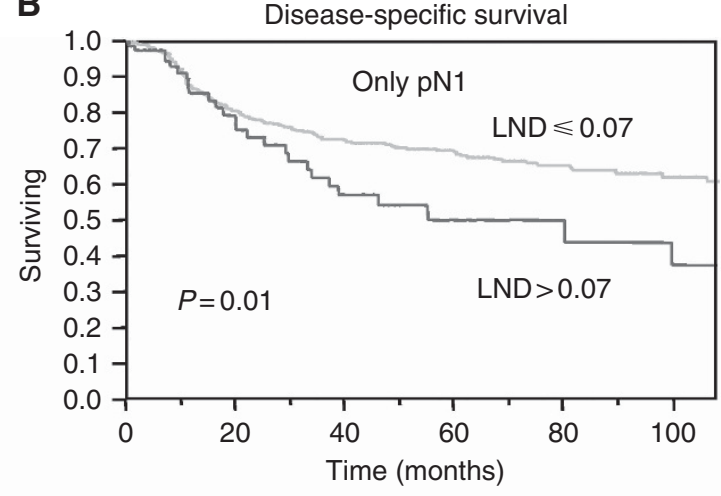

D

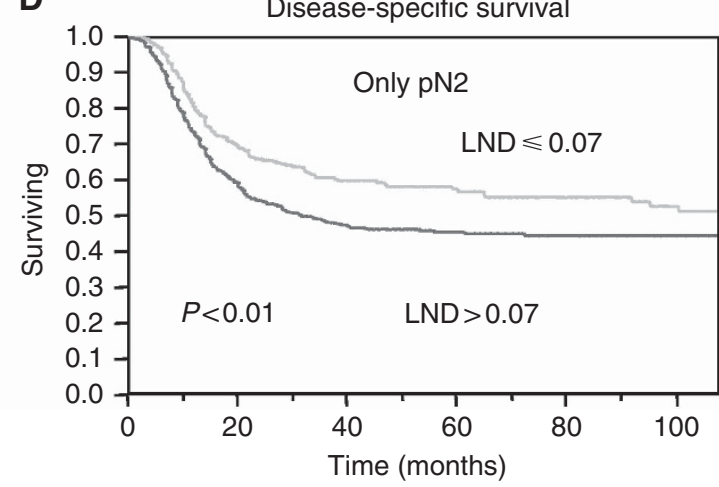

Figure 4. The ability of LND to distinguish between low-risk and high-risk patients within individual pN subgroups. Kaplan-Meier curves of overall and disease-specific survival in a subgroup of patients with pN1 nodal classification ( $\mathbf{A}$ and $\mathbf{C}$ ) and pN2 nodal classification (B and D). LND reliably distinguished between patients in each subgroup with a low risk and those with a high risk for treatment failure $(P<0.05)$.

population (Mamelle et al, 1994; Pentenero et al, 2005). The single most important factor that determines the nodal staging is the nodal sampling procedure. The value of the number of positive nodes as a predictor of outcome for head and neck cancer patients was first suggested by Mamelle et al (1994). Fifteen years later, it was shown for OSCC patients that LND is superior to conventional nodal staging for predicting outcome (Roder et al, 1994; Stein et al, 2003; Kassouf et al, 2006; Herr, 2007; Liao et al, 2012a,b; Ooki et al, 2007; Gil et al, 2009; Kim and Cha, 2012; Kim et al, 2011; Amar et al, 2012).

LND is a mathematical derivation of the ratio between positive lymph nodes and the total number of excised lymph nodes. The cutoff ratio is applicable, for example, in a patient with one positive lymph node among 20 examined, which results in a LND ratio of 0.05 . The ratio of LND weighs three factors that can potentially influence nodal staging: (1) tumour factors (the true number of positive lymph nodes), (2) surgical factors (the actual number of nodes removed during neck dissection) and (3) sampling factors (the completeness of the pathological analysis). We postulated that patients with a higher LND are expected to fare worse than patients with a lower ratio, even when they have a similar $\mathrm{N}$ classification. Previous studies investigated the utility of LND in small cohorts of patients, which were performed by single institutes mostly in the United States and Canada. In the current study, we aimed to investigate the clinical significance of LND in a large collaborative study of 11 cancer centres across the globe. This study provides the first large-scale analysis of LND in patients with OSCC. In the current study, we evaluated the predictive value of the LND compared with the conventional staging system in over 1986 patients from 11 medical centres across the globe. We aimed to determine the ability of the LND to predict OS, DSS and locoregional recurrence-free survival in patients undergoing neck dissection. The results of our multivariate analyses showed that
LND is superior to the conventional $\mathrm{N}$ staging system in predicting OS, DSS and locoregional control. Interestingly, the LND was also a predictor of distance metastases. Most importantly, we were able to show that LND was sensitive enough to identify a subpopulation of patients who are at high risk for tumour recurrence within each $\mathrm{pN}$ classification. Our multivariate analysis showed that LND was a better predictor of outcome than conventional $\mathrm{N} 1$ and $\mathrm{N} 2$ classification in the following groups of patients: those undergoing elective neck dissections, those undergoing therapeutic neck dissections and those receiving adjuvant radiotherapy or chemoradiation. On the foundation of these results, we suggest a modification of the TNM staging classification that is based on LND instead of $\mathrm{pN}$ stage for patients with nodal metastases.

Recent studies have demonstrated slight improvement in 5-year survival rates after adjuvant-concurrent chemoradiation therapy compared with radiotherapy alone for advanced head and neck SCC (Bernier et al, 2004). However, because of the significant morbidity associated with intensification of adjuvant treatment that is adding chemotherapy to radiotherapy - there is still considerable controversy over the pathological characteristics of the tumour that predict the need for more aggressive adjuvant treatment (Bernier et al, 2005). We hypothesise that LND can potentially assist in indentifying patients with poor outcomes and therefore for whom more aggressive adjuvant treatment is needed. Further studies are required to determine whether patients with a high LND will benefit from concurrent chemoradiation therapy. Although our data provide a strong argument in favour of nodal ratios to stratify risk of recurrence, other factors related to nodal status, such as the size and volume of the occupied lymph node, nodal site, presence of occult micrometastases discovered by molecular methods and extent of ECS may also be significant predictors of outcome. We recognise that their interplay needs elaboration. 
We also realise that one of the limitations of this study is the potential of inconsistency in the surgical technique and processing of the pathological specimens that may introduce potential errors. The mean number of lymph nodes removed in our cohort was 33, with a standard deviation of 23 and a range of 2-104. However, fewer than 20 lymph nodes were found in only 771 (21\%) patients, and almost all of them had selective neck dissection. The previously reported mean lymph node yield in a unilateral radical neck dissection ranged from 1 to 97 nodes (Bhattacharyya, 1998; Agrama et al, 2001; Jose et al, 2003). The variations in the number of lymph nodes retrieved from our specimens are, therefore, similar to other studies. Owing to the retrospective nature of the study data regarding ethnicity, primary tumour site, smoking status and alcohol exposure were not available. Yet two-stage random effects analysis revealed minimal heterogeneity betweencentres, and even after we excluded cases with $<20$ lymph nodes from our analysis, LND remained the only significant independent predictor of outcome. Conversely, the significance of LND as a predictor of outcomes in our heterogenous cohort across multiple countries assure the broad applicability of research finding worldwide and might facilitate the uptake of LND as a prognosticator into standard practice in diverse patient populations (Trimble et al, 2009).

In conclusion, we have validated the importance of LND in a multi-institutional international study that represents the largest and most detailed cohort of OSCC to date. The results and detailed statistical analyses show that LND is a useful adjunct to the conventional TNM staging system and that LND may be used to identify patients at high risk of treatment failure and therefore for whom more aggressive adjuvant treatment may be needed.

\section{ACKNOWLEDGEMENTS}

Esther Eshkol is thanked for her editorial assistance. We would like to thank Dr Ester Shabtai and Carmit Rubin (MA), Statistics Services Unit, Tel Aviv, Israel, for the statistical analysis. This research was supported by the Israel Science Foundation, the Israel Cancer Association (grant donated by Ellen and Emanuel Kronitz in memory of Dr Leon Kronitz No. 20090068), the Israeli Ministry of Health (No. 3-7355), the Weizmann Institute - TASMC Joint Grant, the ICRF Barbara S Goodman endowed research career development award (2011-601-BGPC), an Intramural grant from Rambam Medical Center and a grant from the US-Israel Binational Science Foundation.

Novelty and Impact Statements: Squamous cell carcinoma of the oral cavity (OSCC) is the common malignant tumors of the head and neck. Recent data indicate that the conventional staging system does not necessarily predict prognosis in OSCC, especially after adjuvant radiotherapy. In this first multicenter international study, we show that lymph node density is superior to the conventional nodal staging system in predicting outcome.

These new data provide benefits that can advance management of head and neck carcinomas worldwide.

\section{CONFLICT OF INTEREST}

The authors declare no conflict of interest.

\section{REFERENCES}

Agrama MT, Reiter D, Cunnane MF, Topham A, Keane WM (2003) Nodal yield in neck dissection and the likelihood of metastases. Otolaryngol Head Neck Surg 128(2): 185-190.
Agrama MT, Reiter D, Topham AK, Keane WM (2001) Node counts in neck dissection: are they useful in outcomes research? Otolaryngol Head Neck Surg 124(4): 433-435.

Amar A, Rapoport A, Curioni OA, Dedivitis RA, Cernea CR, Brandao LG (2012) The density of metastatic lymph node as prognostic factor in squamous cell carcinoma of the tongue and floor of the mouth. Braz J Otorhinolaryngol 78(3): 86-90.

Ambrosch P, Kron M, Fischer G, Brinck U (1995) Micrometastases in carcinoma of the upper aerodigestive tract: detection, risk of metastasizing, and prognostic value of depth of invasion. Head Neck 17(6): 473-479.

Attaallah W, Gunal O, Manukyan M, Ozden G, Yegen C (2013) Prognostic impact of the metastatic lymph node ratio on survival in rectal cancer. Ann Coloproctol 29(3): 100-105.

Bernier J, Cooper JS, Pajak TF, van Glabbeke M, Bourhis J, Forastiere A, Ozsahin EM, Jacobs JR, Jassem J, Ang KK, Lefebvre JL (2005) Defining risk levels in locally advanced head and neck cancers: a comparative analysis of concurrent postoperative radiation plus chemotherapy trials of the EORTC (\#22931) and RTOG (\#9501). Head Neck 27(10): 843-850.

Bernier J, Domenge C, Ozsahin M, Matuszewska K, Lefebvre JL, Greiner RH, Giralt J, Maingon P, Rolland F, Bolla M, Cognetti F, Bourhis J, Kirkpatrick A, van Glabbeke M (2004) Postoperative irradiation with or without concomitant chemotherapy for locally advanced head and neck cancer. N Engl J Med 350(19): 1945-1952.

Bhattacharyya N (1998) The effects of more conservative neck dissections and radiotherapy on nodal yields from the neck. Arch Otolaryngol Head Neck Surg 124(4): 412-416.

Chen CH, George SL (1985) The bootstrap and identification of prognostic factors via Cox's proportional hazards regression model. Stat Med 4(1): $39-46$.

Cox D (1972) Regression models and life-tables. J R Stat Soc 34(2): 187-220.

DerSimonian R, Laird N (1986) Meta-analysis in clinical trials. Controlled Clin Trials 7(3): 177-188.

Ebrahimi A, Zhang WJ, Gao K, Clark JR (2011) Nodal yield and survival in oral squamous cancer: defining the standard of care. Cancer 117(13): 2917-2925.

Edge SB, Byrd DR, Compton CC, Fritz AG, Greene FL, Trotti A eds. (2010) AJCC Cancer Staging Manual. 7th edn. Springer: New York, NY, USA.

Efron B (1994) An introduction to the Bootstrap. Chapman \& Hall/CRC: Boca Raton, FL, USA.

Espin F, Bianchi A, Llorca S, Feliu J, Palomera E, Garcia O, Remon J, Sunol X (2012) Metastatic lymph node ratio versus number of metastatic lymph nodes as a prognostic factor in gastric cancer. Eur J Surg Oncol 38(6): 497-502.

Etzioni R, Kooperberg C, Pepe M, Smith R, Gann PH (2003) Combining biomarkers to detect disease with application to prostate cancer. Biostatistics 4(4): 523-538.

Fukano H, Matsuura H, Hasegawa Y, Nakamura S (1997) Depth of invasion as a predictive factor for cervical lymph node metastasis in tongue carcinoma. Head Neck 19(3): 205-210.

Gavilan J, Prim MP, De Diego JI, Hardisson D, Pozuelo A (2000) Postoperative radiotherapy in patients with positive nodes after functional neck dissection. Ann Otol Rhinol Laryngol 109(9): 844-848.

Gil Z, Carlson DL, Boyle JO, Kraus DH, Shah JP, Shaha AR, Singh B, Wong RJ, Patel SG (2009) Lymph node density is a significant predictor of outcome in patients with oral cancer. Cancer 115(24): 5700-5710.

Gil Z, Patel SG, Singh B, Cantu G, Fliss DM, Kowalski LP, Kraus DH, Snyderman C, Shah JP. International Collaborative Study G (2007) Analysis of prognostic factors in 146 patients with anterior skull base sarcoma: an international collaborative study. Cancer 110(5): 1033-1041.

group Pn (2007) Guidlines for the Examination and Reporting of Head and Neck Cancer Specimens. pp 1-12. Cancer Network: LEEDS: Yorkshire.

Heagerty PJ, Lumley T, Pepe MS (2000) Time-dependent ROC curves for censored survival data and a diagnostic marker. Biometrics 56(2): 337-344.

Herr HW (2007) The concept of lymph node density-is it ready for clinical practice? J Urol 177(4): 1273-1275. Discussion 1275-1276.

Higgins JP, Thompson SG (2002) Quantifying heterogeneity in a metaanalysis. Stat Med 21(11): 1539-1558.

Jose J, Coatesworth AP, MacLennan K (2003) Cervical metastases in upper aerodigestive tract squamous cell carcinoma: histopathologic analysis and reporting. Head Neck 25(3): 194-197.

Kaplan EL, Meier P (1958) Non-parametric estimation from incomplete observation. JAMA 53(282): 457-481. 
Kassouf W, Leibovici D, Munsell MF, Dinney CP, Grossman HB, Kamat AM (2006) Evaluation of the relevance of lymph node density in a contemporary series of patients undergoing radical cystectomy. J Urol 176(1): 53-57. Discussion 57.

Kim KY, Cha IH (2012) Risk stratification of oral cancer patients using a combined prognostic factor including lymph node density and biomarker. J Cancer Res Clin Oncol 138(3): 483-490.

Kim SY, Nam SY, Choi SH, Cho KJ, Roh JL (2011) Prognostic value of lymph node density in node-positive patients with oral squamous cell carcinoma. Ann Surg Oncol 18(8): 2310-2317.

Lee EK, Herr HW, Dickstein RJ, Kassouf W, Munsell MF, Grossman HB, Dinney CP, Kamat AM (2012) Lymph node density for patient counselling about prognosis and for designing clinical trials of adjuvant therapies after radical cystectomy. BJU Int 110(11 Pt B): E590-E595.

Liao CT, Chang JT, Wang HM, Ng SH, Hsueh C, Lee LY, Lin CH, Chen IH, Huang SF, Cheng AJ, Yen TC (2012a) Survival in squamous cell carcinoma of the oral cavity: differences between pT4 N0 and other stage IVA categories. Cancer 110(3): 564-571.

Liao CT, Hsueh C, Lee LY, Lin CY, Fan KH, Wang HM, Huang SF, Chen IH, Kang CJ, Ng SH, Tsao CK, Huang YC, Yen TC (2012b) Neck dissection field and lymph node density predict prognosis in patients with oral cavity cancer and pathological node metastases treated with adjuvant therapy. Oral Oncol 48(4): 329-336.

Mamelle G, Pampurik J, Luboinski B, Lancar R, Lusinchi A, Bosq J (1994) Lymph node prognostic factors in head and neck squamous cell carcinomas. Am J Surg 168(5): 494-498.

Mantel N (1966) Evaluation of survival data and two new rank order statistics arising in its consideration. Cancer Chem 50(3): 163-170.

Ooki A, Yamashita K, Kobayashi N, Katada N, Sakuramoto S, Kikuchi S, Watanabe M (2007) Lymph node metastasis density and growth pattern as independent prognostic factors in advanced esophageal squamous cell carcinoma. World J Surg 31(11): 2184-2191.

Parsons JT, Mendenhall WM, Stringer SP, Cassisi NJ, Million RR (1997) An analysis of factors influencing the outcome of postoperative irradiation for squamous cell carcinoma of the oral cavity. Int J Radiat Oncol Biol Phys 39(1): 137-148.

Passoni NM, Abdollah F, Suardi N, Gallina A, Bianchi M, Tutolo M, Fossati N, Gandaglia G, Salonia A, Freschi M, Rigatti P, Montorsi F, Briganti A (2013) Head-to-head comparison of lymph node density and number of positive lymph nodes in stratifying the outcome of patients with lymph node-positive prostate cancer submitted to radical prostatectomy and extended lymph node dissection. Urologic oncology. PII: S1078-1439(12)00355-9.

Patel SG, Shah JP (2005) TNM staging of cancers of the head and neck: striving for uniformity among diversity. CA Cancer J Clin 55(4): 242-258, quiz 261-2, 264.

Pentenero M, Gandolfo S, Carrozzo M (2005) Importance of tumor thickness and depth of invasion in nodal involvement and prognosis of oral squamous cell carcinoma: a review of the literature. Head Neck 27(12): 1080-1091.

Peto R, Pike MC, Armitage P, Breslow NE, Cox DR, Howard SV, Mantel N, McPherson K, Peto J, Smith PG (1977) Design and analysis of randomized clinical trials requiring prolonged observation of each patient. II. analysis and examples. Br J Cancer 35(1): 1-39.

Robbins KT, Shaha AR, Medina JE, Califano JA, Wolf GT, Ferlito A, Som PM, Day TA. Committee for Neck Dissection Classification AH, Neck S (2008) Consensus statement on the classification and terminology of neck dissection. Arch Otolaryngol 134(5): 536-538.

Roder JD, Busch R, Stein HJ, Fink U, Siewert JR (1994) Ratio of invaded to removed lymph nodes as a predictor of survival in squamous cell carcinoma of the oesophagus. Br J Surg 81(3): 410-413.

Rudoltz MS, Benammar A, Mohiuddin M (1995) Does pathologic node status affect local control in patients with carcinoma of the head and neck treated with radical surgery and postoperative radiotherapy? Int J Radiat Oncol Biol Phys 31(3): 503-508.

Sayed SI, Sharma S, Rane P, Vaishampayan S, Talole S, Chaturvedi P, Chaukar D, Deshmukh A, Agarwal JP, D'Cruz AK (2013) Can metastatic lymph node ratio (LNR) predict survival in oral cavity cancer patients? J Surg Oncol 108(4): 256-263.

Shah JP, Gil Z (2009) Current concepts in management of oral cancersurgery. Oral Oncology 45(4-5): 394-401.

Shingaki S, Takada M, Sasai K, Bibi R, Kobayashi T, Nomura T, Saito C (2003) Impact of lymph node metastasis on the pattern of failure and survival in oral carcinomas. Am J Surg 185(3): 278-284.

Stein JP, Cai J, Groshen S, Skinner DG (2003) Risk factors for patients with pelvic lymph node metastases following radical cystectomy with en bloc pelvic lymphadenectomy: concept of lymph node density. J Urol 170(1): $35-41$.

Stukel TA, Demidenko E, Dykes J, Karagas MR (2001) Two-stage methods for the analysis of pooled data. Stat Med 20(14): 2115-2130.

Trimble EL, Abrams JS, Meyer RM, Calvo F, Cazap E, Deye J, Eisenhauer E, Fitzgerald TJ, Lacombe D, Parmar M, Seibel N, Shankar L, Swart AM, Therasse P, Vikram B, von Frenckell R, Friedlander M, Fujiwara K, Kaplan RS, Meunier F (2009) Improving cancer outcomes through international collaboration in academic cancer treatment trials. J Clin Oncol 27(30): 5109-5114.

von Elm E, Altman DG, Egger M, Pocock SJ, Gotzsche PC, Vandenbroucke JP (2007) The Strengthening the Reporting of Observational Studies in Epidemiology (STROBE) statement: guidelines for reporting observational studies. Lancet 370(9596): 1453-1457.

Wu SG, He ZY, Li Q, Sun JY, Li FY, Lin Q, Lin HX, Guan XX (2013) Prognostic value of metastatic axillary lymph node ratio for Chinese breast cancer patients. PLoS One 8(4): e61410.

Xiao LB, Yu JX, Wu WH, Xu FF, Yang SB (2011) Superiority of metastatic lymph node ratio to the 7th edition UICC $\mathrm{N}$ staging in gastric cancer. World J Gastroenterol 17(46): 5123-5130.

Yako-Suketomo H, Marugame T (2008) Comparison of time trends in lip cancer incidence (1973-97) in East Asia, Europe and USA, from Cancer Incidence in Five Continents, Vols IV-VIII. Jap J Clin Oncol 38(6): 456-457.

This work is published under the standard license to publish agreement. After 12 months the work will become freely available and the license terms will switch to a Creative Commons AttributionNonCommercial-Share Alike 3.0 Unported License.

Supplementary Information accompanies this paper on British Journal of Cancer website (http://www.nature.com/bjc) 